\title{
Sugar-sweetened carbonated drinks consumption, body composition and aerobic fitness in 9-10-year-old schoolchildren
}

\author{
L. M. Boddy ${ }^{1,2}$, A. F. Hackett ${ }^{1,2}$ and G. Stratton ${ }^{1}$ \\ ${ }^{1}$ Research into Activity and Children's Health Group, Liverpool John Moores University, Henry Cotton Campus, \\ 15-21 Webster Street, Liverpool L2 3ET, UK and ${ }^{2}$ Centre for Tourism, Consumer and Food Studies, \\ Liverpool John Moores University, IM Marsh Campus, Barkhill Rd, Liverpool L17 6BD, UK
}

The increased prevalence of obesity and overweight observed in children in recent years is often attributed to poor dietary habits and insufficient physical activity. Furthermore, the declining levels of physical fitness observed in children ${ }^{(1)}$, are often attributed to similar factors. Sugar-sweetened carbonated drinks consumption has been investigated in obesity studies in the past ${ }^{(2)}$, representing a key food often cited in the obesity 'epidemic'. The aim of the present study was to compare measures of adiposity and fitness between participants who reportedly consumed sugar-sweetened carbonated drinks with those who did not. Data were collected over four academic years (2004-8) and were available for 10027 (5052 boys and 4975 girls) 9-10-year-old participants. Stature and body mass recorded at SportsLinx ${ }^{(3)}$ fitness sessions were used to calculate BMI. Waist circumference, hip circumference, subscapular and triceps skinfolds were also recorded. Performance on the $20 \mathrm{~m}$ multistage-shuttle runs $(20 \mathrm{mMST})$ test was used as a marker of aerobic fitness. Sugar-sweetened carbonated drinks intake was assessed using the SportsLinx Lifestyles Survey. The survey is a food intake questionnaire that asks children to confirm if they had consumed a selection of foods in the $24 \mathrm{~h}$ before questionnaire completion, and the survey has been previously investigated for reliability in this population ${ }^{(4)}$. ANOVA was completed to assess differences in body composition and aerobic fitness between consumers and non-consumers of sugar-sweetened carbonated drinks. Anthropometric and 20 mMST data for consumers and non-consumers separated by gender are shown in the Table.

\begin{tabular}{|c|c|c|c|c|c|c|c|c|}
\hline \multirow[b]{3}{*}{ Variable } & \multicolumn{4}{|c|}{ Boys } & \multicolumn{4}{|c|}{ Girls } \\
\hline & \multicolumn{2}{|c|}{ Consumers } & \multicolumn{2}{|c|}{ Non-consumers } & \multicolumn{2}{|c|}{ Consumers } & \multicolumn{2}{|c|}{ Non-consumers } \\
\hline & Mean & SD & Mean & SD & Mean & SD & Mean & $\mathrm{SD}$ \\
\hline BMI $\left(\mathrm{kg} / \mathrm{m}^{2}\right)$ & 17.9 & 3.2 & 18.2 & 3.5 & 18.4 & 3.6 & 18.6 & 3.5 \\
\hline Waist circumference $(\mathrm{cm})$ & 63.2 & 9.4 & 64.2 & 9.5 & 63.8 & 9.5 & 64.8 & 9.3 \\
\hline Hip circumference $(\mathrm{cm})$ & 74.5 & 8.2 & 75.7 & 8.3 & 75.6 & 9.1 & 76.6 & 8.6 \\
\hline Subscapular skinfold (mm) & 8.8 & 6.1 & 9.3 & 6.6 & 11.0 & 7.3 & 11.4 & 7.2 \\
\hline Triceps skinfold (mm) & 13.4 & 6.3 & 13.8 & 6.6 & 16.2 & 6.5 & 16.6 & 6.5 \\
\hline 20 mMST performance (shuttles) & 40.9 & 18.9 & 40.3 & 19.1 & 28.6 & 13.2 & 28.4 & 13.5 \\
\hline
\end{tabular}

When data were pooled for boys and girls results described significantly lower BMI, hip circumference, subscapular and triceps skinfold thicknesses and higher 20 mMST values in the consumers group $(P \leq 0.05)$. When boys and girls were analysed separately, boys who consumed carbonated drinks had significantly lower BMI, and skinfold values than non-consumers $(P \leq 0.05)$. For girls, triceps skinfolds were lower in the consumers group $(P \leq 0.05)$.

These findings suggest that the relationship between sugar-sweetened carbonated drinks consumption and body composition and aerobic fitness may be less straightforward than is commonly assumed. Fitter children may be habitually more physically active and thirstier as a result. Thirstier children may consume greater volumes of beverages. Furthermore, the venues that children attend to participate in physical activities and sports, e.g. leisure centres, typically stock sugar-sweetened carbonated drinks in vending machines. In addition, the selfreported methods used to assess intakes of beverages may warrant further development.

1. Stratton G, Canoy D, Boddy LM et al. (2007) Int J Obes (Lond) 31, 1172-1178.

2. James J \& Kerr D (2005) Int J Obes (Lond) 29, S54-S57.

3. Taylor S, Hackett A, Stratton G et al. (2004) Educ Health 22, 3-7.

4. Johnson B, Hackett A, Bibby A et al. (1999) J Hum Nutr Diet 12, 307-316. 